\title{
Excited electronic state decomposition mechanisms of clusters of dimethylnitramine and aluminum
}

\author{
ANUPAM BERA and ATANU BHATTACHARYA* \\ Department of Inorganic and Physical Chemistry, Indian Institute of Science, Bangalore 560012, India \\ e-mail: atanub@ipc.iisc.ernet.in
}

MS received 5 September 2014; revised 14 October 2014; accepted 14 October 2014

\begin{abstract}
In this report, electronically non-adiabatic decomposition pathways of clusters of dimethylnitramine and aluminum (DMNA-Al and DMNA- $\mathrm{Al}_{2}$ ) are discussed in comparison to isolated dimethylnitramine (DMNA). Electronically excited state processes of DMNA-Al and DMNA- $\mathrm{Al}_{2}$ are explored using the complete active space self-consistent field (CASSCF) and the restricted active space self-consistent field (RASSCF) theories, respectively. Similar to the nitro-nitrite isomerization reaction pathway of DMNA, DMNA$\mathrm{Al}_{\mathrm{n}}$ clusters also exhibit isomerization pathway. However, it involves several other steps, such as, first Al-O bond dissociation, then $\mathrm{N}-\mathrm{N}$ bond dissociation followed by isomerization and finally $\mathrm{NO}$ elimination. Furthermore, DMNA-Al $l_{n}$ clusters exhibit overall exothermic decomposition reaction pathway and isolated DMNA shows overall endothermic reaction channel.
\end{abstract}

Keywords. Excited electronic state; Non-adiabatic; CASSCF and RASSCF calculation; DMNA-Al cluster.

\section{Introduction}

Molecular energetic material (EM), composed of oxidizer and fuel constituents in one molecule (e.g., nitroglycerine, RDX, HMX, etc.), releases a large amount of stored chemical energy via decomposition. Dissociation of EM can be initiated by sparks, shocks or arcs that can excite energetic molecule to the electronically excited states. ${ }^{1}$ For an example, recent $a b$ initio calculations show that shock compression at a pressure of $30 \mathrm{GPa}$ or above can cause an electronic excitation equivalent to $2-5 \mathrm{eV},{ }^{\text {le }}$ which is comparable to the excitation energies of the low lying excited electronic states of many energetic molecules, such as RDX (hexahydro-1,3,5-trinitro1,3,5-triazine), HMX (Octahydro-1,3,5,7-tetranitro1,3,5,7-tetrazocine, $\left.\mathrm{C}_{4} \mathrm{H}_{8} \mathrm{~N}_{8} \mathrm{O}_{8}\right)$ and CL-20 (2,4,6,8, 10,12-hexanitro-2,4,6,8,10,12-hexaazaisowurtzitane). ${ }^{2}$ Therefore, excited electronic states play an essential role in the initial steps of decomposition of these molecules. Recently, Bernstein and his co-workers have firmly established, both theoretically and experimentally, that conical intersection, which creates a funnellike topography of potential energy surfaces (PESs) due to the crossing of multidimensional electronic PESs, is a controlling factor in the excited electronic state decomposition of energetic molecules. ${ }^{3}$ Thus, the initial decomposition steps of energetic molecules are

\footnotetext{
*For correspondence
}

electronically non-adiabatic in nature due to the involvement of more than one electronic PES.

For a long time, molecular EMs were the centre of attraction in high energy applications (explosives, rocket propellants, etc.). However, recently, composite metalized energetic materials (mEMs) ${ }^{4}$ containing metal particles (e.g., Fe, Al, etc.) and traditional molecular EMs, have drawn significant attention due to their superior performance over molecular EMs. ${ }^{5}$ They are found to release more energy. ${ }^{6}$ Compared to the molecular EMs, mEMs release energy at much faster rates with more complete combustion. Enhanced performance of mEM over molecular EMs is often accounted for the exothermicity of oxide formation reaction (e.g., heat of formation of alumina from aluminum $\left(4 \mathrm{Al}+3 \mathrm{O}_{2} \rightarrow\right.$ $2 \mathrm{Al}_{2} \mathrm{O}_{3}$ ) is $-1676 \mathrm{~kJ} / \mathrm{mol}^{7}$ ) for constituent metal during combustion. This thermodynamic explanation is well accepted among researchers in the energetic material community. However, the other side of the problem has never been seriously considered, particularly in the context of their excited electronic state decomposition; namely, presence of metal (particle) surface can also alter the electronically excited electronic state decomposition mechanisms and dynamics of molecular EMs. How do $\mathrm{Al}$ atoms affect the excited electronic state decomposition mechanisms and dynamics of molecular EMs? This question has remained unanswered in literature, so far. Perhaps, one of the important reasons is that the exploration of excited-electronic-state PESs of large energetic molecules, such as RDX, are not 
directly feasible using only conventional quantum mechanical (QM) methodologies which can describe an excited state with adequate accuracy. ${ }^{2,3}$ In general, multiconfiguration-based ab initio quantum mechanical methods, such as complete-active-space self-consistent field (CASSCF) and CAS perturbation theory (CASMP2/ CASPT2), are more accurate for exploring excitedelectronic-state PESs but they are still too expensive to apply to large energetic molecules, such as RDX. The requirement of a very large active space to perform the CASSCF calculation for large energetic molecules complicates the effort.

RDX, HMX and CL-20 are well known nitramine $\left(\mathrm{N}-\mathrm{NO}_{2}\right)$-based energetic materials. Their chemical structures are depicted in figure 1 . These molecules possess a number of $\mathrm{N}-\mathrm{NO}_{2}$ (nitramine) energetic moieties with complex structures and that is why a structurally simple analogue molecule dimethylnitramine (DMNA) (figure 1), containing only one $\mathrm{N}-\mathrm{NO}_{2}$ energetic moiety, is often subjected to laboratory-based detailed experimental and theoretical study to explore the intrinsic decomposition mechanisms and dynamics of a nitramine moiety. ${ }^{8}$ As often aluminum (Al) powder or particles is mixed with nitramine EMs (such as, RDX) in high energy rocket propellant applications, ${ }^{9}$ DMNA- $\mathrm{Al}_{n}$ clusters can be considered as a simple analogues metalized energetic system. To date, the electronically excited state decomposition of molecular isolated DMNA has been investigated experimentally and theoretically, in details. ${ }^{8}$ Thermally activated (ground electronic state) decomposition of nitramine energetic materials at the $\mathrm{Al}(111)$ surface has also been studied. ${ }^{9 b, c}$ However, excited electronic state decomposition of DMNA-Al $l_{n}$ clusters is hitherto-unexplored. Furthermore, a comparative study of the excited electronic state decomposition mechanisms of DMNA- $\mathrm{Al}_{\mathrm{n}}$
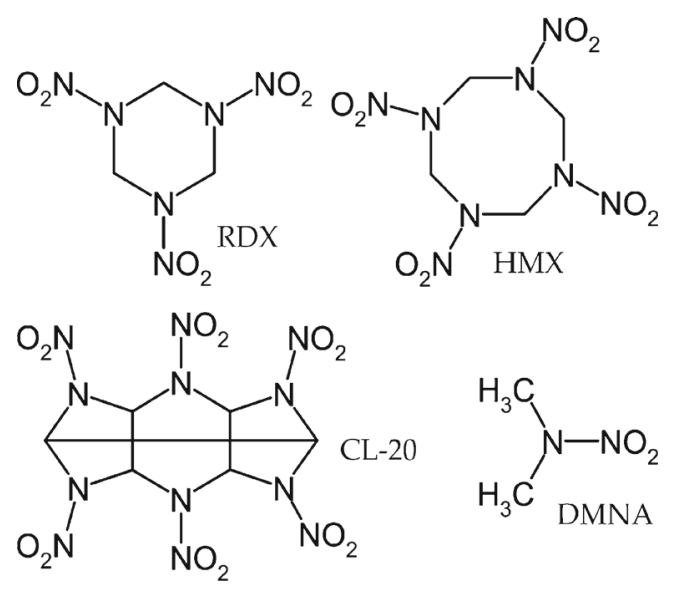

Figure 1. Chemical structure of nitramine-based energetic molecules (RDX, HMX and CL-20) and a simple analogue molecule dimethyl nitramine (DMNA). clusters and that of isolated DMNA has not been performed yet.

In the present work, excited electronic state decomposition pathways of DMNA-Al and DMNA- $\mathrm{Al}_{2}$ have been explored utilizing complete active space selfconsistent field (CASSCF) and restricted active space self-consistent field theories, respectively. Different basis sets are utilized to investigate the effect of enlarging basis sets in the calculations. Effect of dynamic correlation is also examined using CASMP2 level of theory. Both DMNA-Al and DMNA- $\mathrm{Al}_{2}$ exhibit electronically non-adiabatic decomposition pathways, involving several steps such as, Al-O bond dissociation, N-N bond dissociation and nitro-nitrite isomerization followed by NO elimination. On the other hand, isolated molecular DMNA exhibits only nitro-nitrite isomerization followed by $\mathrm{NO}$ elimination (rendering $\mathrm{NO}$ as initial decomposition product). Furthermore, overall electronically non-adiabatic reaction of DMNA-Al clusters is predicted to be exothermic; whereas, isolated DMNA features endothermic, electronically non-adiabatic decomposition pathway. Therefore, present results suggest that the decomposition behaviour of nitramine energetic moiety can be completely altered in presence of $\mathrm{Al}$ atoms. To the best of our knowledge, this is the first report on electronically excited state decomposition of metalized nitramine energetic system.

\section{Theoretical Procedure}

All geometry optimizations at the ground and excited electronic states of DMNA-Al are performed at the complete active space self-consistent field (CASSCF) theory with 6-31G(d) basis set (denoted as CASSCF/6$31 \mathrm{G}(\mathrm{d})$ ) using Gaussian 09. ${ }^{10}$ The active space used in the CASSCF calculation for DMNA-Al comprises 13 electrons distributed in 11 active orbitals, denoted as CASSCF $(13,11)$. Orbitals used in the active space are one $\mathrm{N}$ non-bonding $\mathrm{nS}_{\mathrm{N}}$ orbital, one Al non-bonding $\mathrm{nS}_{\mathrm{Al}}$, one NO bonding orbitals $\sigma_{\mathrm{NO}}$, two NNO bonding orbitals $\sigma_{\mathrm{NNO}}$, one $\mathrm{AlO}$ bonding $\sigma_{\mathrm{AlO}}$, one $\mathrm{O}$ nonbonding $\mathrm{n} \sigma_{\mathrm{O}}$ orbital, two $\mathrm{NO}$ anti-bonding orbitals $\sigma_{\mathrm{NO}}^{*}$, one $\mathrm{NN}$ anti-bonding $\sigma_{\mathrm{NN}}^{*}$, one anti-bonding $\sigma_{\mathrm{AlO}}^{*}$, as illustrated in figure 2. Similar active space was previously used by Bhattacharya et al., ${ }^{3,8 a}$ for the computation of excited electronic states of isolated DMNA. To understand the effect of different basis sets in the present CASSCF calculations, computational results obtained using different basis sets, such as 6-31G(d) and 6-31+G(d) and 6-311++G(d,p), are compared and contrasted. The energy profile diagrams with respect to optimization steps, connecting FC 


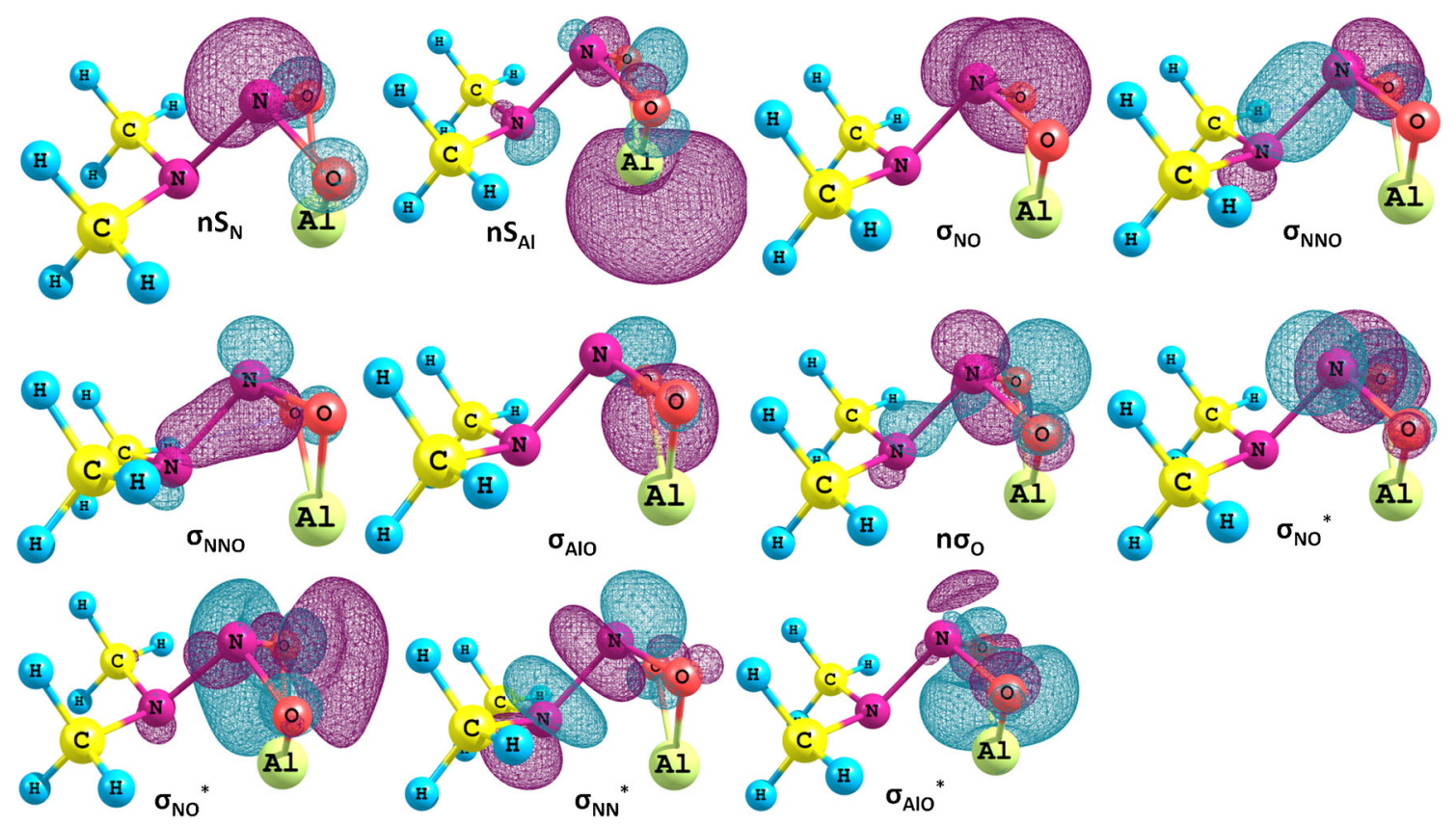

Figure 2. Orbitals used in the active space in the CASSCF calculations for DMNA-Al. The active space comprises 13 electrons which are distributed in 11 active orbitals for DMNA-Al. Orbitals are computed at the CASSCF $(13,11) / 6-31 G(d)$ level of theory.

points and related conical intersections on the $\mathrm{D}_{2}$ and $\mathrm{D}_{1}$ surfaces of DMNA-Al, are also calculated at the CASSCF $(13,11) / 6-31 G(d)$ level. Effect of dynamic correlation in the present calculation is investigated at the CASMP2 level of theory. ${ }^{11}$ In order to perform computation at the CASMP2 level of theory, we have reduced the active space to $(11,8)$.

All geometry optimizations on the ground and the excited electronic state potential energy surfaces of DMNA- $\mathrm{Al}_{2}$ are executed by restricted active space self-consistent field (RASSCF) method with STO$3 \mathrm{G}$ basis set and then energies of the critical points are recalculated using 6-31G(d) basis set (denoted as CASSCF(RASSCF)//6-31G(d)) using Gaussian 09. ${ }^{10}$ RASSCF is an extension of the CASSCF calculation in which three restricted active spaces are selected: RAS1, RAS2 and RAS3; the orbitals used in difference RA spaces are depicted in figure 3. The active space used in the RASSCF calculation consists of 18 electron distributed in 15 orbitals and is denoted as CASSCF $(18,15, \operatorname{RASSCF}(1,4,1,4)) / / 6-31 \mathrm{G}(\mathrm{d})$, in which the RAS1 houses 4 orbitals, the RAS2 contains 7 orbitals (Full CI expansion is performed in the RAS2 space) and the RAS3 consists of 4 orbitals. The energy profile diagrams, connecting $\mathrm{S}_{2, \mathrm{FC}}$ to $\left(\mathrm{S}_{2} / \mathrm{S}_{1}\right)_{\mathrm{CI}}$ and $\mathrm{S}_{1, \mathrm{FC}}$ to $\left(\mathrm{S}_{1} / \mathrm{S}_{0}\right)_{\mathrm{CI}}$, are obtained using the CASSCF $(18,15, \operatorname{RASSCF}(1,4,1,4)) / / 6-31 \mathrm{G}(\mathrm{d})$ level of theory.

Vertical excitation energies, at both CASSCF and RASSCF methods, are calculated by state-averaging over the ground and excited states with equal weights for each state. Critical points (minima and conical intersections) are optimized by using the algorithm implemented in Gaussian09. Some of the reaction pathways of DMNA-Al are explored through potential energy scanning. A relaxed potential energy scan is performed using Z-matrix by changing the scan variables (respective bond distance). For comparison, some of the critical points on the ground state surface of DMNA-Al are also explored at the MP2/6-31(d) level of theory.

\section{Results and Discussion}

\subsection{DMNA-Al}

In order to optimize DMNA-Al, we have placed one $\mathrm{Al}$ atom at different sites of $\mathrm{N}-\mathrm{NO}_{2}$ moiety; but, finally all the initial geometries converged to the CASSCFoptimized ground state geometry $\left(\mathrm{D}_{0, \mathrm{Min} 1}\right)$, as illustrated in figure 4 , which shows a non-planar $\mathrm{N}-\mathrm{NO}_{2}$ moiety, in which $\mathrm{Al}$ atom forms strong $\mathrm{Al}-\mathrm{O}$ bond with $\mathrm{O}$ atoms. The dihedral angle, NNOO, predicted at CASSCF level of theory, is found to be $\sim 100^{\circ}$. Structures of DMNA-Al and isolated DMNA, optimized at the MP2/6-31G(d) level of theory, are also given in figure 4, for comparison. CASSCF- and MP2-optimized structures for DMNA-Al are in good agreement with each other. However, MP2 results for DMNA-Al and DMNA differ significantly. The primary difference 

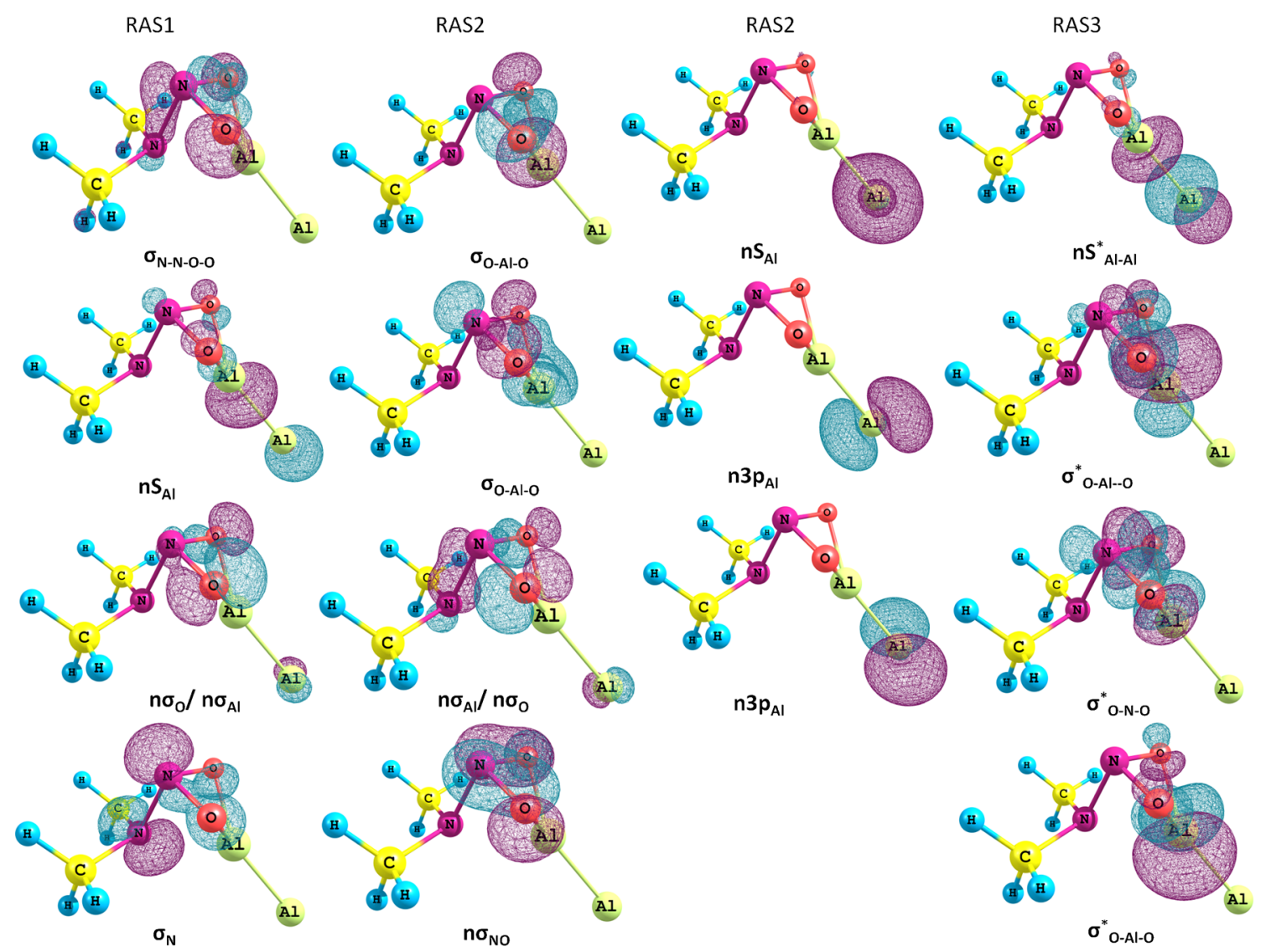

Figure 3. Orbitals used in the active space in the RASSCF calculations for DMNA- $\mathrm{Al}_{2}$. The active space comprises 18 electrons which are distributed in 15 active orbitals for $\mathrm{DMNA}-\mathrm{Al}_{2}$. Orbitals are computed at the CASSCF(18,15,RASSCF(1,4,1,4))//6-31G(d) level of theory.

between DMNA-Al and isolated DMNA structures is found to be in the $\mathrm{N}-\mathrm{NO}_{2}$ region: DMNA exhibits a planar $\mathrm{N}-\mathrm{NO}_{2}$ moiety, whereas, that of DMNA-Al is non-planar due to presence of $\mathrm{Al}$ atom. Furthermore, both the $\mathrm{N}-\mathrm{N}$ and the $\mathrm{N}-\mathrm{O}$ bonds are elongated in DMNA-Al complex in comparison with that of isolated DMNA.

The vertical excitation energies for DMNA-Al, computed at the CASSCF(13,11)/6-31G(d) optimized Franck-Condon geometry (FC geometry at ground state minimum), are listed in table 1 . Present calculations show that two lowest lying excited electronic states $\left(\mathrm{D}_{1, \mathrm{FC}}\right.$ and $\left.\mathrm{D}_{2, \mathrm{FC}}\right)$ for DMNA-Al possess vertical excitation energies of 4.13 and $4.59 \mathrm{eV}$, respectively. Furthermore, the excitation from the $\mathrm{D}_{0, \mathrm{Min} 1}$ to the $\mathrm{D}_{1, \mathrm{FC}}$ corresponds to $\left(\mathrm{n} \sigma_{\mathrm{O}} \rightarrow \sigma_{\mathrm{Al}-\mathrm{O}}^{*}\right)$ electronic excitation and that to $\mathrm{D}_{2, \mathrm{FC}}$ features $\left(\sigma_{\mathrm{Al}-\mathrm{O}} \rightarrow \sigma_{\mathrm{Al}-\mathrm{O}}^{*}\right)$ electronic excitation.

On the other hand, the vertical excitation energies of isolated DMNA, corresponding to two lowestlying excited states computed at the $\operatorname{CASSCF}(14,11) / 6-$ $31 \mathrm{G}(\mathrm{d})$ level of theory, are $5.13\left(\mathrm{n} \sigma_{\mathrm{O}} \rightarrow \pi_{\mathrm{ONO}} *\right)$ and $5.92 \mathrm{eV}\left(\mathrm{n} \sigma_{\mathrm{O}} \rightarrow \pi_{\mathrm{ONO}} *\right)$, respectively. This comparison of vertical excitation energies and characters of electronic excitation between DMNA-Al and isolated DMNA clearly indicates that vertical excitation energies of DMNA are lowered in the presence of $\mathrm{Al}$ atom. Furthermore, table 1 suggests that enlarging the basis set in the present CASSCF computation for DMNA-Al does not have significant effect, which was also observed for earlier CASSCF computation for isolated DMNA. ${ }^{8 a}$ In addition, table 1 presents evidences that CASMP2-computed energies are not changing significantly, estimating the values within an average range of $\pm 0.7 \mathrm{eV}$.

A number of critical points on the electronically excited and ground state PESs of DMNA-Al, such as $\left(\mathrm{D}_{2} / \mathrm{D}_{1}\right)_{\mathrm{CI}},\left(\mathrm{D}_{1} / \mathrm{D}_{0}\right)_{\mathrm{CI}}, \mathrm{D}_{0, \mathrm{Min} 2}$, and $\mathrm{D}_{0, \mathrm{Min} 3}$, are optimized at the CASSCF $(13,11) / 6-31 \mathrm{G}(\mathrm{d})$ level of theory. Respective optimized geometries are depicted in figure 5 with important bond lengths and bond angles. The energy profile diagrams with respect to optimization steps, connecting FC points and related conical intersections on the $\mathrm{D}_{2}$ and $\mathrm{D}_{1}$ surfaces, as calculated at the $\operatorname{CASSCF}(13,11) / 6-31 \mathrm{G}(\mathrm{d})$ level, are explicitly depicted in figure $6 \mathrm{a}$ and $\mathrm{b}$. As evident in these two 

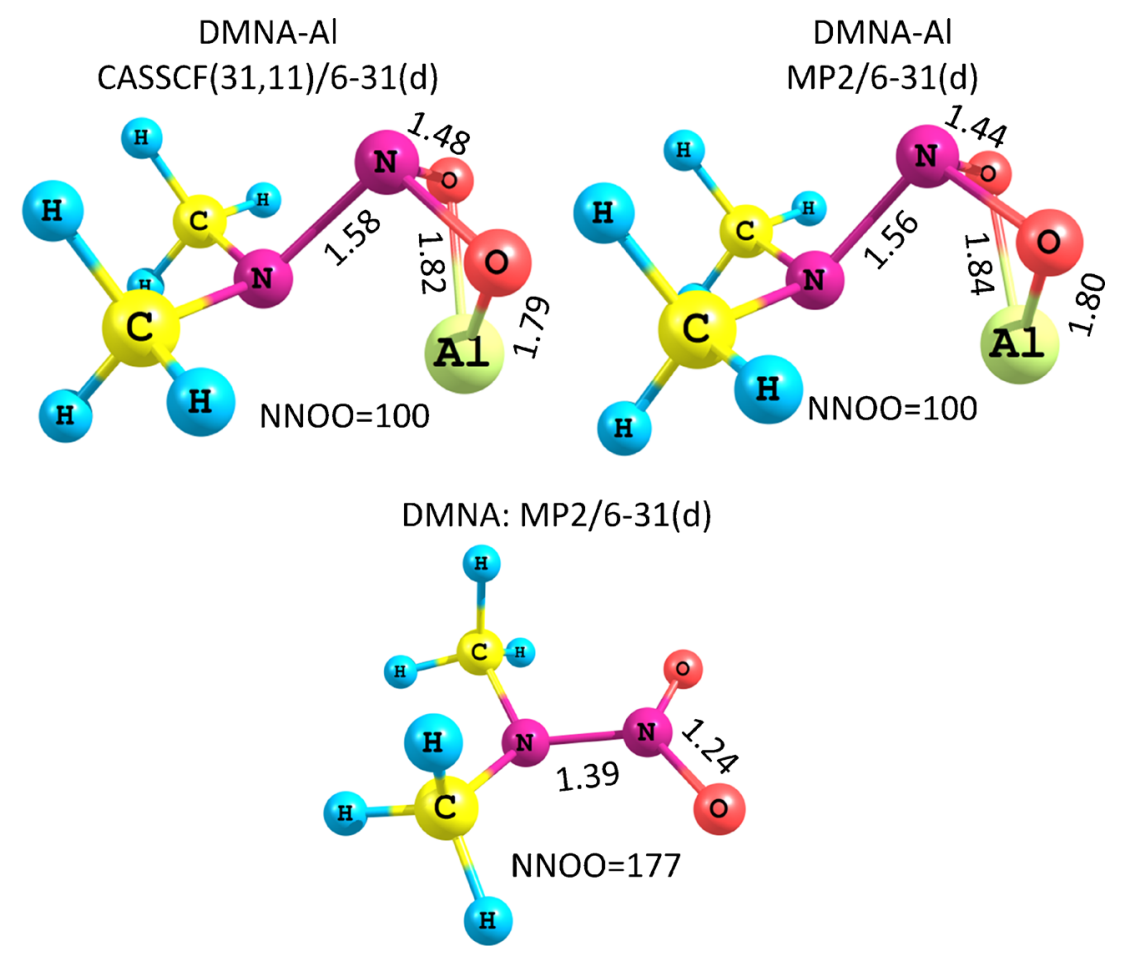

Figure 4. Ground state optimized geometries of DMNA-Al at the CASSCF/6-31G(d) and MP2/6-31G(d) levels of theory (top) and that of DMNA optimized at MP2/6-31G(d) (bottom). Relevant structural parameters are also given. The primary difference between DMNA-Al and DMNA is found in the dihedral angle of NNOO.

figures, the decay paths connecting the FC point of the $\mathrm{D}_{2}$ state to the $\left(\mathrm{D}_{2} / \mathrm{D}_{1}\right)_{\mathrm{CI}}$ on the $\mathrm{D}_{2}$ surface and the same from the $\mathrm{FC}$ point of the $\mathrm{D}_{1}$ state to the $\left(\mathrm{D}_{1} / \mathrm{D}_{0}\right)_{\mathrm{CI}}$ feature downhill processes. Structural evolutions through these critical points, as also illustrated in figure 5, suggests that the first step in the excited state decomposition of DMNA-Al is Al-O bond dissociation, which finally results in non-adiabatic transition of the complex from the upper electronic states to the ground state surface, rendering $\mathrm{D}_{0, \mathrm{Min} 2}$ geometry. The optimized geometries at the $\left(\mathrm{D}_{2} / \mathrm{D}_{1}\right)_{\mathrm{CI}}$ and the $\left(\mathrm{D}_{1} / \mathrm{D}_{0}\right)_{\mathrm{CI}}$ show Al1-O2 bond distance of 2.96 and $2.41 \AA$, respectively. Similarly, the $\mathrm{D}_{0, \text { Min2 }}$ optimized geometry exhibits Al1-O2 bond distance of $3.69 \AA$, while the same at the FC point shows A11-O2 bond distance of $1.82 \AA$.

Subsequent N-N bond dissociation path on the $\mathrm{D}_{0}$ surface from $\mathrm{D}_{0, \operatorname{Min} 2}$, which is depicted in figure $6 \mathrm{c}$, is explored using relaxed potential energy scanning. The scan results indicate that this process is associated with an activation energy barrier of $0.94 \mathrm{eVwith}$ respect to the $\mathrm{D}_{0, \mathrm{Min} 2}$. The $\mathrm{N}-\mathrm{N}$ bond dissociation channel finally results in nitro-nitrite isomerization,

Table 1. Relative energies (in eV) of different critical points, calculated with respect to the $\mathrm{D}_{0, \text { Min1 }}$ for DMNA-Al, as computed at the CASSCF(13,11)/6-31G(d), CASSCF(13,11)/6-31+G(d), CASSCF $(13,11) / 6-311++\mathrm{G}(\mathrm{d}, \mathrm{p})$ and CASMP2(11,8)/6-31G(d) levels of theory.

\begin{tabular}{|c|c|c|c|c|}
\hline State/CI & $\begin{array}{l}\Delta \mathrm{E}(\mathrm{eV}) \\
\mathrm{CAS} / 6-31 G(d)\end{array}$ & $\begin{array}{l}\Delta \mathbf{E}(\mathbf{e V}) \\
\text { CAS/6-31+G(d) }\end{array}$ & $\begin{array}{l}\Delta \mathrm{E}(\mathrm{eV}) \\
\mathrm{CAS} / 6-311++\mathbf{G}(\mathrm{d}, \mathrm{p})\end{array}$ & $\begin{array}{l}\triangle \mathrm{E}(\mathrm{eV}) \\
\text { CASMP2/6-31G(d) }\end{array}$ \\
\hline$D_{1, F C}$ & 4.13 & 4.21 & 4.22 & 5.05 \\
\hline $\mathbf{D}_{2, \mathrm{FC}}$ & 4.59 & 4.67 & 4.67 & 5.32 \\
\hline$\left(\mathbf{D}_{2} / \mathbf{D}_{1}\right)_{\mathrm{CI}}$ & 2.63 & 2.67 & 3.71 & 3.43 \\
\hline$\left(\mathrm{D}_{1} / \mathrm{D}_{0}\right)_{\mathrm{CI}}$ & 1.96 & 1.98 & 2.56 & 2.81 \\
\hline$D_{0, \operatorname{Min} 2}$ & 0.43 & 0.41 & 1.27 & 0.91 \\
\hline$D_{0, M i n} 3$ & -1.82 & -1.88 & -1.39 & -1.13 \\
\hline TS & 1.37 & 1.35 & 1.27 & 2.01 \\
\hline NO-elimination & -0.74 & -0.76 & -0.89 & -0.80 \\
\hline $\mathrm{NO}_{2}$-elimination & 1.89 & 1.93 & 2.20 & 1.95 \\
\hline
\end{tabular}



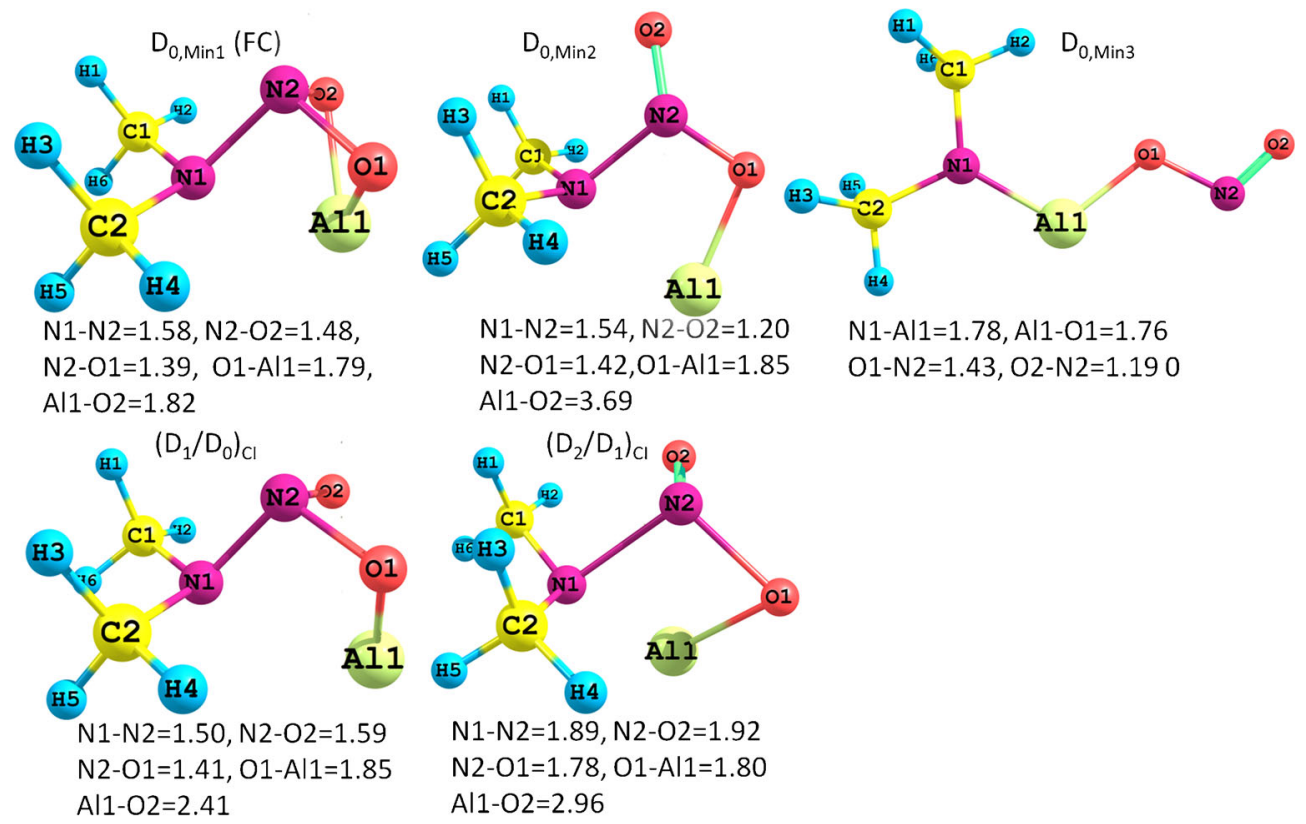

Figure 5. Geometries of DMNA-Al at the different critical points on the excited as well as ground state potential energy surfaces, as found at the CASSCF(13,11)/6-31G(d) level of theory.

rendering $\mathrm{D}_{0, \text { Min3 } 3}$. The $\mathrm{D}_{0, \text { Min3 }}$ geometry, optimized at the $\operatorname{CASSCF}(13,11) / 6-31 \mathrm{G}(\mathrm{d})$ level of theory, which is illustrated in figure 5, shows nitrite form which is similar to that of isolated DMNA. ${ }^{8 a}$ Following nitronitrite isomerization, $\mathrm{D}_{0, \mathrm{Min} 3}$ can dissociate to either $\mathrm{NO}_{2}$ or NO. In order to understand these two different possible channels on the ground state PES of DMNA$\mathrm{Al}$, we have explored the dissociation limits associated with the eliminations of $\mathrm{NO}$ and $\mathrm{NO}_{2}$ from $\mathrm{D}_{0, \mathrm{Min} 3}$ using relaxed potential energy scan at the CASSCF/6-31G(d) level of theory. The scan results, depicted in figure $6 \mathrm{~d}$ and 6 e, estimate that the limits to $\mathrm{NO}$ and $\mathrm{NO}_{2}$ eliminations with respect to the $\mathrm{D}_{0, \mathrm{Min} 3}$ are 1.08 and $3.71 \mathrm{eV}$, respectively. Note that these values in table 1 are given with respect to the $\mathrm{D}_{0, \operatorname{Min} 1}$.

The N-N bond dissociation, followed by NO elimination or $\mathrm{NO}_{2}$ elimination channel on the $\mathrm{D}_{0}$ surface, is also explored at the MP2/6-31G(d) level of theory. Results are summarized in table 2. The activation energy associated with nitro-nitrite isomerization of DMNA-Al at the MP2 level is calculated to be $0.52 \mathrm{eV}$, with respect to the $\mathrm{D}_{0, \mathrm{Minn}}$. The MP2 level of theory also estimates dissociation limits to the $\mathrm{NO}$ and $\mathrm{NO}_{2}$ eliminations following nitro-nitrite isomerization as 0.56 and $1.86 \mathrm{eV}$, respectively, with respect to the $\mathrm{D}_{0, \text { Min3 } 3}$. Thus, the N-N bond dissociation energy barrier and the dissociation limits to the $\mathrm{NO}$ and $\mathrm{NO}_{2}$ eliminations, following nitro-nitrite isomerization, for DMNA-Al, predicted at the MP2, are in good agreement with that estimated at the CASSCF level of theory. More comparison of MP2 and CASSCF results for other critical points can be found in the table 2 .

To summarize the above results, a schematic one dimensional plot of the multidimensional electronic PESs $\left(\mathrm{D}, \mathrm{D}_{1}\right.$, and $\left.\mathrm{D}_{2}\right)$ of DMNA-Al is depicted in figure 7. Upon electronic excitation of DMNA-Al to the FC point of the $\mathrm{D}_{2}$ state, the complex can follow a barrier-less dissociation pathway from the FC point of $\mathrm{D}_{2}$ state to the $\left(\mathrm{D}_{2} / \mathrm{D}_{1}\right)_{\mathrm{CI}}$, and then from the $\left(\mathrm{D}_{2} / \mathrm{D}_{1}\right)_{\mathrm{CI}}$ to the $\left(\mathrm{D}_{1} / \mathrm{D}_{0}\right)_{\mathrm{CI}}$. This pathway ultimately results in Al-O bond dissociation in DMNA-Al complex, rendering $\mathrm{D}_{0, \text { Min } 2}$ geometry on the ground electronic state surface. The Al-O bond dissociation channel is predicted to be purely electronically non-adiabatic process, as this pathway involves a number of conical intersections or crossing of electronically excited state surfaces.

The $\mathrm{D}_{0, \text { Min } 2}$ is an important intermediate in the overall decomposition reaction of DMNA-Al following electronic excitation. This intermediate is rendered after DMNA-Al complex comes back to the ground state through the $\left(\mathrm{D}_{1} / \mathrm{D}_{0}\right)_{\mathrm{CI}}$ (undergoing Al-O bond dissociation). Subsequent N-N bond dissociation channel can be opened up on the ground state PES, which finally results in exothermic nitro-nitrite isomerization. The CASSCF level of theory predicts that the nitrite form $\left(\mathrm{D}_{0, \mathrm{Min} 3}\right)$ of DMNA-Al complex is stabilized by 1.82 e.V(MP2 estimates $0.86 \mathrm{eV}$ ) with respect to the $\mathrm{D}_{0, \mathrm{Min} 1}(\mathrm{FC})$. Similar 

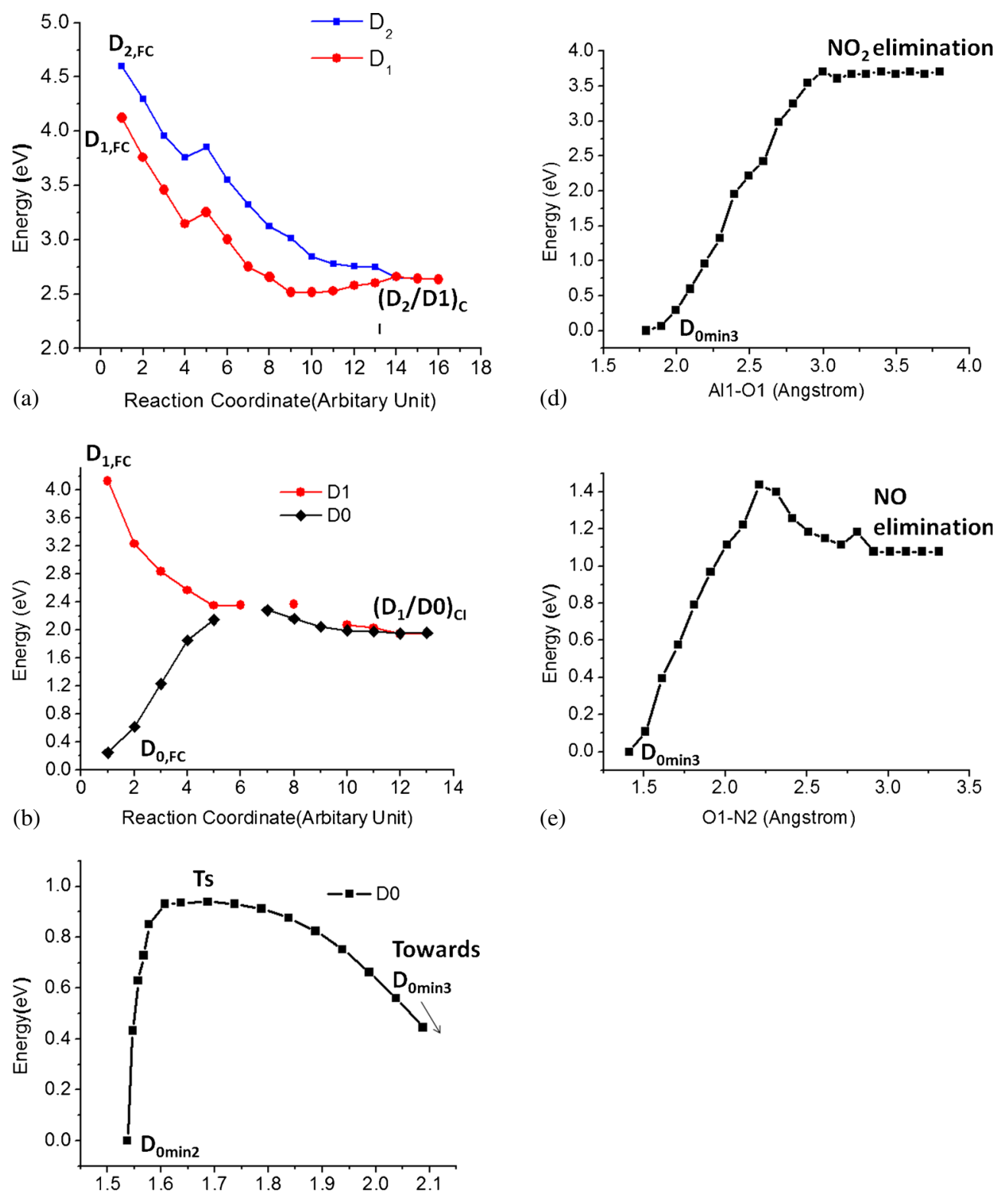

(c)

N1-N2 (Angstrom)

Figure 6. Energy profile diagrams obtained during optimization, computed at the CASSCF $(13,11) / 6-31 G(d)$ : (a) from $\mathrm{D}_{2, \mathrm{FC}}$ and $\mathrm{D}_{1, \mathrm{FC}}$ to $\left(\mathrm{D}_{2} / \mathrm{D}_{1}\right)_{\mathrm{CI}}$; (b) from $\mathrm{D}_{1, \mathrm{FC}}$ and $\mathrm{D}_{0, \mathrm{FC}}$ to $\left(\mathrm{D}_{1} / \mathrm{D}_{0}\right)_{\mathrm{CI}}$. Potential energy surface scans along (c) N1-N2 bond distance from $\mathrm{D}_{0, \text { Min2 }}$, and along (d) Al1-O1 bond distance ( $\mathrm{NO}_{2}$ elimination) and (e)O1-N2 bond distance (NO elimination) from $\mathrm{D}_{0, \operatorname{Min} 3}$ on the ground state potential energy surface.

nitro-nitrite isomerization was found to be endothermic process for isolated DMNA. ${ }^{8 a}$ Consequential decomposition of $\mathrm{D}_{0, \text { Min3 } 3}$ can lead to either the $\mathrm{NO}$ or the $\mathrm{NO}_{2}$ elimination. However, both the CASSCF and the MP2 levels of theory predict that the NO elimination is associated with the lowest energy barrier $(1.08$ and $0.56 \mathrm{eV}$ with respect to $\mathrm{D}_{0, \mathrm{Min} 3}$, predicted at the CASSCF and MP2 levels, respectively). Therefore, the overall non-adiabatic decomposition scheme (as also illustrated in Figure 7) for DMNA-Al from the $\mathrm{D}_{2, \mathrm{FC}}$ is as follows:

$$
\begin{aligned}
\text { DMNA-Al, }\left(\mathrm{D}_{2, \mathrm{FC}}\right) & \rightarrow\left(\mathrm{D}_{2} / \mathrm{D}_{1}\right) \mathrm{CI} \rightarrow\left(\mathrm{D}_{1} / \mathrm{D}_{0}\right) \mathrm{CI} \\
& \rightarrow \text { DMNA-Al }\left(\mathrm{D}_{0, \mathrm{Min} 2}\right) \rightarrow \mathrm{TS} \\
& \rightarrow \text { nitrite }\left(\mathrm{D}_{0, \mathrm{Min} 3}\right) \rightarrow \mathrm{NO}
\end{aligned}
$$

Another possible decomposition pathway, predicted at the CASSCF level of theory, can start from the FC 
Table 2. Relative energies (in eV) of different critical points on the $\mathrm{D}_{0}$ ground potential energy surface, calculated with respect to the $\mathrm{D}_{0, \text { Min1 }}$ for DMNA-Al complex, as computed at MP2/6-31G(d) and CASSCF $(13,11) / 6-31 G(d)$ level of theory.

\begin{tabular}{lcc}
\hline & \multicolumn{2}{l}{ Level of theory } \\
\cline { 2 - 3 } Geometry & MP2/6-31G(d) & CASSCF $(13,11) / 6-31 \mathrm{G}(\mathrm{d})$ \\
\hline $\mathrm{D}_{0, \text { Min2 }}$ & 0.91 & 0.43 \\
$\mathrm{D}_{0, \text { Min3 }}$ & -0.86 & -1.82 \\
$\mathrm{TS}$ & 1.43 & 1.37 \\
$\mathrm{NO}$ Elimination & -0.30 & -0.74 \\
$\mathrm{NO}_{2}$ Elimination & 1.01 & 1.89 \\
\hline
\end{tabular}

point on the $\mathrm{D}_{1}$ surface and follow the $\left(\mathrm{D}_{1} / \mathrm{D}_{0}\right)_{\mathrm{CI}}$ point. After coming to the ground state following this pathway, DMNA-Al complex, can pursue the same decomposition channel discussed above.

In the present context, it would be interesting to compare the electronically excited state decomposition behaviour of DMNA-Al with that of isolated DMNA. A schematic energy profile diagram of the electronic PESs $\left(\mathrm{S}, \mathrm{S}_{1}\right.$, and $\left.\mathrm{S}_{2}\right)$ of isolated DMNA, computed at the CASSCF $(14,11) / 6-31 \mathrm{G}(\mathrm{d})$, is plotted in figure 8 , for comparison. Isolated DMNA exhibits that vertical excitation to the $\mathrm{FC}$ point of the $\mathrm{S}_{2}$ state can potentially lead the molecule to undergo a non-adiabatic nitro-nitrite isomerization through the $\left(\mathrm{S}_{2} / \mathrm{S}_{1}\right)_{\mathrm{CI}}$ conical intersection. After crossing the $\left(\mathrm{S}_{2} / \mathrm{S}_{1}\right)_{\mathrm{CI}}$, DMNA can isomerize to nitrite form on the $S_{1}$ excited state surface. Another possible decomposition pathway from the FC point of the $S_{2}$ surface would be nonadiabatic deactivation of the molecule to the $S_{1}$ surface through the $\left(\mathrm{S}_{2} / \mathrm{S}_{1}\right)_{\mathrm{X}}$ conical intersection, followed by another surface crossing through the $\left(\mathrm{S}_{1} / \mathrm{S}\right)_{\mathrm{CI}}$ conical intersection. This pathway can finally result in nitro-nitrite isomerization on the $\mathrm{S}$ surface. Overall isomerization process, either on the excited state

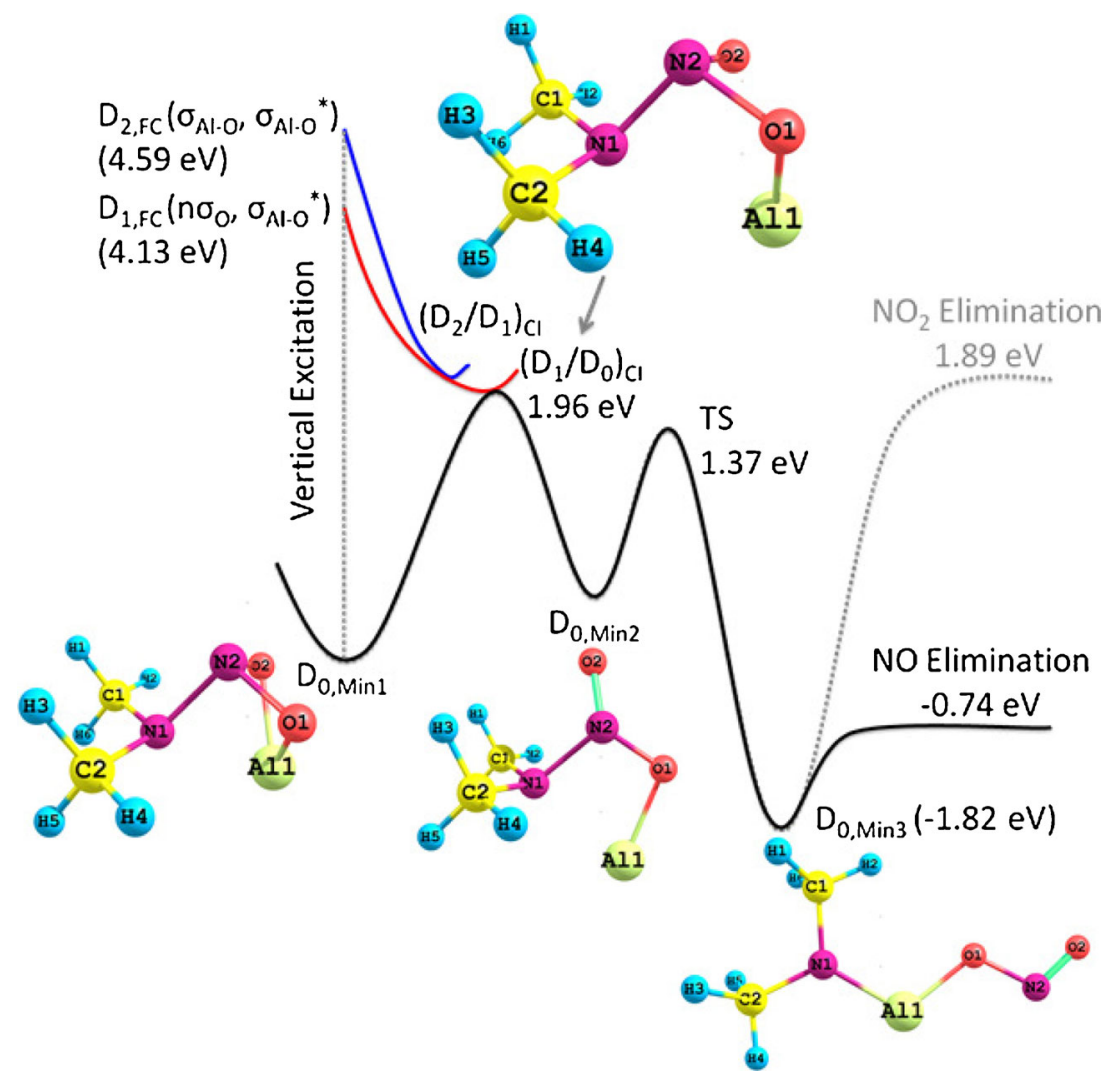

Figure 7. One dimensional plot of the multidimensional electronic potential energy surfaces of DMNA-Al complex, computed at the CASSCF $(13,11) / 6$ $31 \mathrm{G}(\mathrm{d})$ level of theory. 


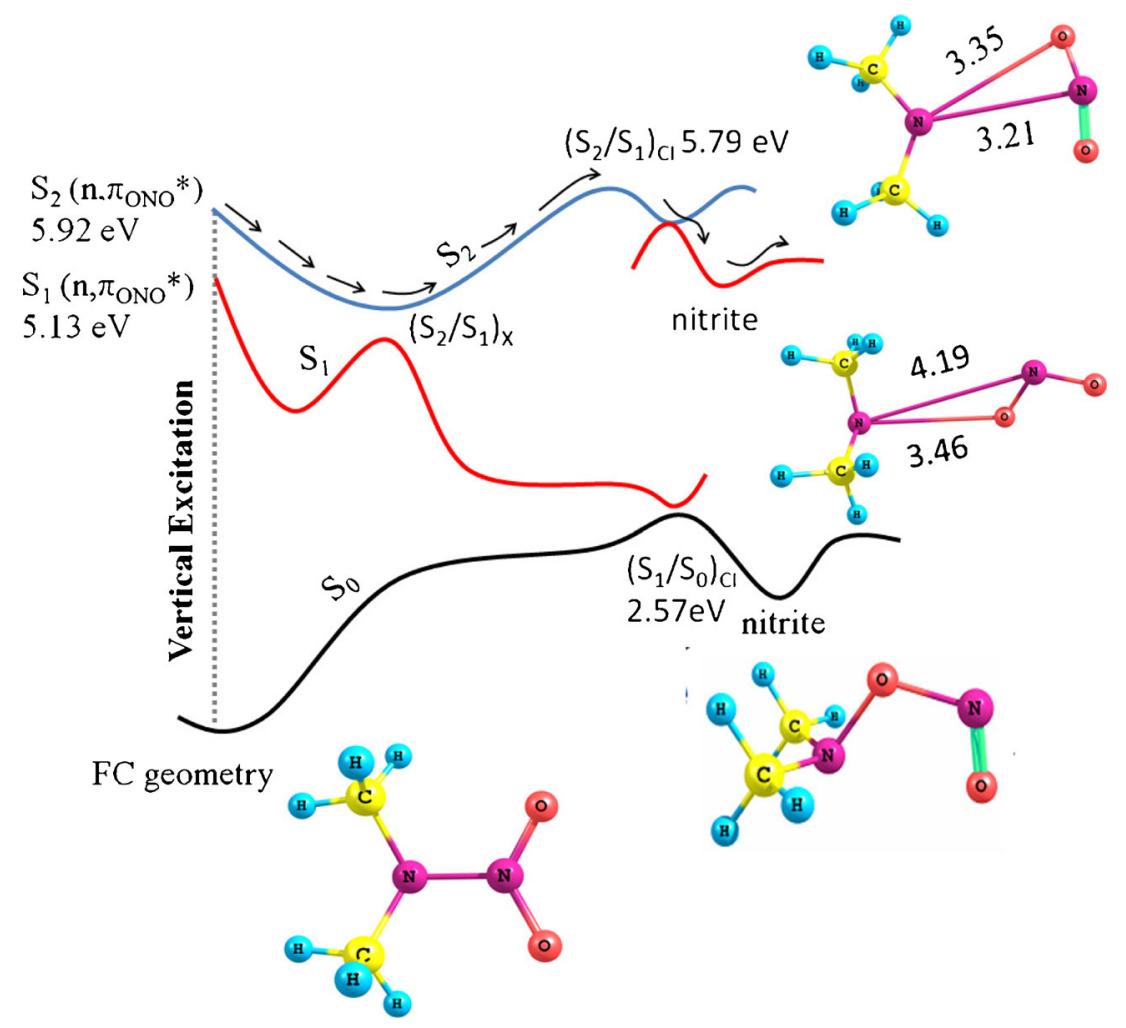

Figure 8. One dimensional plot of the multidimensional electronic potential energy surfaces of DMNA, as computed at the CASSCF $(14,11) / 6-31 \mathrm{G}(\mathrm{d})$ level of theory.

surface or on ground state surface, for DMNA is predicted to be an endothermic reaction, as opposed to the exothermic nitro-nitrite isomerization of DMNA-Al complex.

\subsection{DMNA-Al}

Excited electronic state potential energy surfaces of DMNA- $\mathrm{Al}_{2}$ are explored at the RASSCF level of

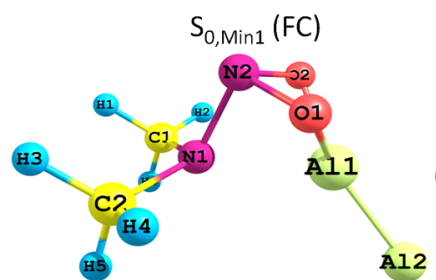

$\mathrm{N} 1-\mathrm{N} 2=1.56, \mathrm{~N} 2-\mathrm{O} 2=1.44$, $\mathrm{N} 2-\mathrm{O} 1=1.44, \mathrm{O} 1-\mathrm{Al} 1=1.77$, Al1-O2=1.77, Al1-Al2=2.46

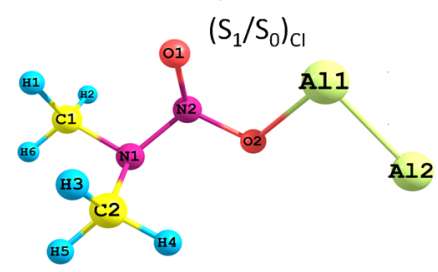

$\mathrm{N} 1-\mathrm{N} 2=1.47, \mathrm{~N} 2-\mathrm{O} 2=1.42$

$\mathrm{N} 2-\mathrm{O} 1=1.38$, O1-Al1 $=1.85$

$\mathrm{Al} 1-\mathrm{O} 2=2.50, \mathrm{Al} 1-\mathrm{Al} 2=2.51$

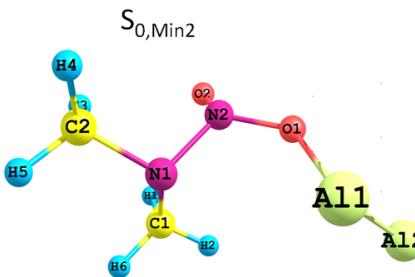

$\mathrm{N} 1-\mathrm{N} 2=1.59, \mathrm{~N} 2-\mathrm{O} 2=1.28$

$\mathrm{N} 2-\mathrm{O} 1=1.42, \mathrm{O} 1-\mathrm{Al} 1=1.92$

Al1-O2=4.09, Al1-Al2=2.50 $\left(\mathrm{S}_{2} / \mathrm{S}_{1}\right)_{\mathrm{Cl}}$

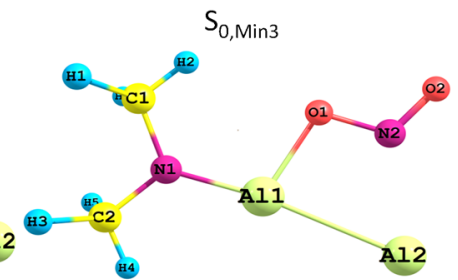

$\mathrm{N} 1-\mathrm{Al} 1=1.80, \mathrm{Al}-\mathrm{O} 1=1.91$

$\mathrm{O} 1-\mathrm{N} 2=1.33, \mathrm{O} 2-\mathrm{N} 2=1.22$

$\mathrm{Al} 1-\mathrm{Al} 2=2.76$

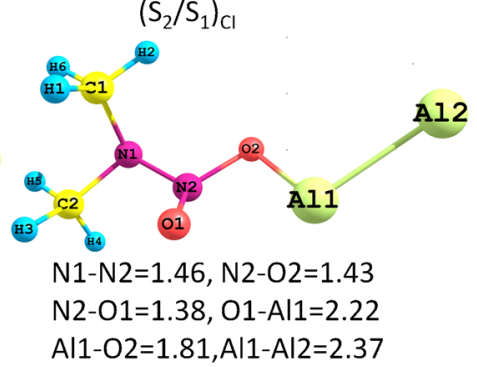

Figure 9. Geometries of $\mathrm{DMNA}-\mathrm{Al}_{2}$ at different critical points on the excited as well as ground state potential energy surfaces, as calculated at the CASSCF $(18,15$, RASSCF $(1,4,1,4)) / 6-31 G(d)$ level of theory. 
Table 3. Relative energies (in $\mathrm{eV}$ ) of different critical points, calculated with respect to the $\mathrm{S}_{0, \mathrm{Min} 1}$ forDMNA- $\mathrm{Al}_{2}$ complex, as computed at $\operatorname{CASSCF}(18,15, \operatorname{RASSCF}(1,4$, $1,4)) / / 6-31 \mathrm{G}(\mathrm{d})$.

\begin{tabular}{lc}
\hline State/CI & $\Delta \mathbf{E}(\mathbf{e V})$ \\
\hline $\mathrm{S}_{1, \mathrm{FC}}$ & 4.19 \\
$\mathrm{~S}_{2, \mathrm{FC}}$ & 6.40 \\
$\left(\mathrm{~S}_{2} / \mathrm{S}_{1}\right)_{\mathrm{CI}}$ & 3.60 \\
$\left(\mathrm{~S}_{1} / \mathrm{s}_{0}\right)_{\mathrm{CI}}$ & 2.01 \\
$\mathrm{~S}_{0, \mathrm{Min} 2}$ & 1.1 \\
$\mathrm{~S}_{0, \text { Min3 }}$ & -2.14 \\
$\mathrm{TS}$ & 2.89 \\
$\mathrm{NO}$-elimination & -1.48 \\
$\mathrm{NO}_{2}$-elimination & 3.80 \\
\hline
\end{tabular}

theory. However, to reduce the computational time, we have optimized critical points using STO-3G basis set and then recalculated the energy using 6-31G(d) basis set. The ground state optimized geometry $\left(\mathrm{S}_{0, \min 1}\right)$ of DMNA- $\mathrm{Al}_{2}$ is depicted in figure 9, in which DMNA molecule is placed at one end of the $\mathrm{Al}_{2}$ dimer. The $\mathrm{Al}-\mathrm{Al}$ bond distance is estimated to be $2.46 \AA$ at the $\operatorname{CASSCF}(18,15, \operatorname{RASSCF}(1,4,1,4)) / / 6-31 \mathrm{G}(\mathrm{d})$ level of theory. The NNOO dihedral angle is calculated to be $97^{\circ}$, which indicates that both DMNA-Al and DMNA- $\mathrm{Al}_{2}$ features non-planar $\mathrm{NNO}_{2}$ moiety in presence of $\mathrm{Al}$ atoms.
The vertical excitation energies for DMNA- $\mathrm{Al}_{2}$, computed at the CASSCF $(18,15, \operatorname{RASSCF}(1,4,1,4)) / / 6$ $31 \mathrm{G}(\mathrm{d}) \mathrm{FC}$ geometry, are listed in table 3, which shows that two lowest lying excited electronic states $\left(\mathrm{S}_{1, \mathrm{FC}}\right.$ and $\mathrm{S}_{2, \mathrm{FC}}$ ) for DMNA- $\mathrm{Al}_{2}$ possess vertical excitation energies of 4.19 and $6.4 \mathrm{eV}$, respectively. Therefore, the $\mathrm{S}_{1, \mathrm{FC}}$ excitation energies of DMNA-Al and DMNA$\mathrm{Al}_{2}$ do not change significantly. However, the $\mathrm{S}_{2, \mathrm{FC}}$ excitation energies for DMNA-Al And DMNA- $\mathrm{Al}_{2}$ are significantly different. The $S_{1, \mathrm{FC}}$ and $S_{2, \mathrm{FC}}$ points for DMNA- $\mathrm{Al}_{2}$ correspond to the electronic excitation from $\left(\sigma_{\mathrm{NNOO}}+\sigma_{\mathrm{OAlO}}+\sigma_{\mathrm{NO}}\right)$ to $\left(3 \mathrm{p}_{\mathrm{Al}}+\sigma_{\mathrm{AlAl}}^{*}+\sigma_{\mathrm{OAlO}}^{*}\right)$ and from $\left(\sigma_{\mathrm{NNOO}}+\sigma_{\mathrm{OAlO}}+\mathrm{n} \sigma_{\mathrm{O}}, \mathrm{n} \sigma_{\mathrm{Al}}\right)$ to $\left(3 \mathrm{p}_{\mathrm{Al}}+\sigma_{\mathrm{OAlO}}^{*}\right)$, respectively. This determination of excited electronic state character for the $S_{1}$ and $S_{2}$ states of DMNA- $\mathrm{Al}_{2}$ suggests that electronic excitation in DMNA- $\mathrm{Al}_{2}$ mostly actives $\sigma_{\mathrm{OAIO}}$ bond.

The PESs of DMNA- $\mathrm{Al}_{2}$ are made up of several critical points, such as $\left(\mathrm{S}_{2} / \mathrm{S}_{1}\right)_{\mathrm{CI}},\left(\mathrm{S}_{1} / \mathrm{S}_{0}\right)_{\mathrm{CI}}, \mathrm{TS}, \mathrm{S}_{0, \mathrm{Min} 2}$, and $\mathrm{S}_{0, \text { Min3 } 3}$. Their structures are optimized at the CASSCF(18,15,RASSCF $(1,4,1,4)) / / 6-31 G(d)$ level of theory and are illustrated in figure 9 . The relative energies of different critical points with respect to the $\mathrm{S}_{0, \text { Min } 1}$ is given in table 3. Similar to DMNA-Al, the optimized geometries of DMNA-Al $\mathrm{l}_{2}$ at the $\left(\mathrm{S}_{1} / \mathrm{S}_{0}\right)_{\mathrm{CI}}$ and $\left(\mathrm{S}_{1} / \mathrm{S}_{0}\right)_{\mathrm{CI}}$ conical intersections suggest that $\mathrm{Al}-\mathrm{O}$ bond dissociation is the initial step in the excited electronic state decomposition of DMNA- $\mathrm{Al}_{2}$. A schematic

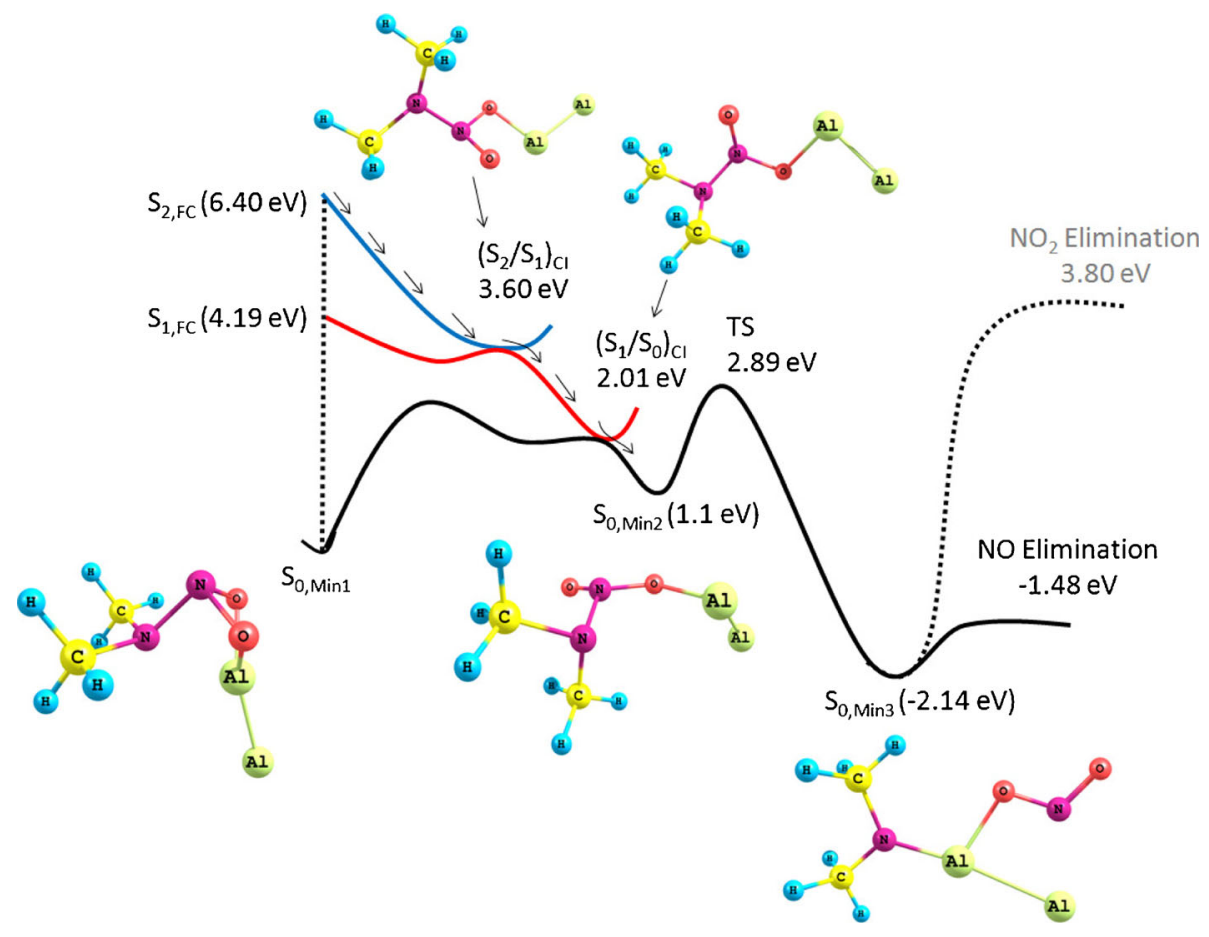

Figure 10. One dimensional plot of the multidimensional electronic potential energy surfaces of DMNA-Al 2 complex, computed at the $\operatorname{CASSCF}(18,15, \operatorname{RASSCF}(1,4$, $1,4)) / / 6-31 \mathrm{G}(\mathrm{d})$ level of theory. 
one-dimensional plot of the multi-dimensional singlet potential energy surfaces of DMNA- $\mathrm{Al}_{2}$ is depicted in figure 10. After vertical excitation to the $S_{2, \mathrm{FC}}$ point, the complex can undergo a barrier-less downhill nonadiabatic transition from the $S_{2}$ PES to the $S_{1}$ PES via the $\left(\mathrm{S}_{2} / \mathrm{S}_{1}\right)_{\mathrm{CI}}$. Then the complex can experience another non-adiabatic transition from the $S_{1}$ PES to the $S_{0}$ PES via the $\left(S_{1} / S_{0}\right)_{C I}$, which can finally results in formation of $S_{0, \min 2}$. The pathways from the $S_{2}$ and $S_{1}$ potential energy surfaces to the $S_{0}$ potential surface have been calculated at the CASSCF $(18,15, \operatorname{RASSCF}(1,4,1,4)) / / 6-$ $31 \mathrm{G}(\mathrm{d})$ level, which are depicted in figure $11 \mathrm{a}$ and $\mathrm{b}$. The pathway connecting the $S_{2, F C}$ point and the $\left(S_{2} / S_{1}\right)_{C I}$ and finally the $\left(\mathrm{S}_{1} / \mathrm{S}_{0}\right)_{\mathrm{CI}}$ supports an Al-O bond dissociation as the initial step in the excited electronic state decomposition of DMNA- $\mathrm{Al}_{2}$. Subsequent N-N bond dissociation channel on the ground state potential energy surface of DMNA- $\mathrm{Al}_{2}$ possesses an activation energy barrier of $1.79 \mathrm{eV}$. The nitrite isomerized $\left(\mathrm{S}_{0, \text { min3 }}\right)$ geometry of $\mathrm{DMNA}-\mathrm{Al}_{2}$ is also found to be extremely stable, similar to that of DMNA-Al. The activation barrier of consequential NO elimination is estimated to be $0.66 \mathrm{eV}$, while $5.94 \mathrm{eV}$ is found for the $\mathrm{NO}_{2}$ elimination pathway with respect to the $\mathrm{S}_{0, \min 3}$. Thus, the overall excited electronic state decomposition mechanism for DMNA- $\mathrm{Al}_{2}$ system along the NO elimination pathway is also found to be exothermic in nature, similar to DMNA-Al system. The non-adiabatic decomposition scheme (as also illustrated in figure 10) for DMNA- $\mathrm{Al}_{2}$ can be written as:

$$
\begin{aligned}
\mathrm{DMNA}-\mathrm{Al}_{2}\left(\mathrm{~S}_{2, \mathrm{FC}}\right) & \rightarrow\left(\mathrm{S}_{2} / \mathrm{S}_{1}\right) \mathrm{CI} \rightarrow\left(\mathrm{S}_{1} / \mathrm{S}_{0}\right) \mathrm{CI} \\
& \rightarrow \mathrm{DMNA}-\mathrm{Al}_{2}\left(\mathrm{~S}_{0, \mathrm{Min} 2}\right) \\
& \rightarrow \mathrm{TS}_{2} \rightarrow \operatorname{nitrite}\left(\mathrm{S}_{0, \mathrm{Min} 3}\right) \rightarrow \mathrm{NO}
\end{aligned}
$$

\section{Conclusions}

In the present article, we have addressed, for the first time, the electronically non-adiabatic decomposition behaviour of model nitramine metalized energetic systems: DMNA-Al and DMNA- $\mathrm{Al}_{2}$ clusters. The excited electronic state decomposition pathways for DMNA-Al were explored at the $\operatorname{CASSCF}(13,11) / 6-31 \mathrm{G}(\mathrm{d})$ level of theory and that of DMNA- $\mathrm{Al}_{2}$ was investigated at the $\operatorname{CASSCF}(18,15, \operatorname{RASSCF}(1,4,1,4)) / / 6-31 \mathrm{G}(\mathrm{d})$ level of theory. We have compared these results with that of isolated DMNA in order to understand the role of $\mathrm{Al}$ atom in the overall electronically non-adiabatic decomposition mechanisms of metalized nitramine energetic systems.

The electronic potential energy surfaces $\left(\mathrm{D}_{0}, \mathrm{D}_{1}\right.$, and $\left.\mathrm{D}_{2}\right)$ for DMNA-Al and that $\left(\mathrm{S}_{0}, \mathrm{~S}_{1}\right.$, and $\left.\mathrm{S}_{2}\right)$ for DMNA$\mathrm{Al}_{2}$ are found to be highly coupled, yielding various conical intersections between two electronic potential energy surfaces. This offers these complexes a direct minimum energy non-adiabatic pathway from the upper electronic to the lower ground states. The final decomposition product for DMNA- $\mathrm{Al}_{\mathrm{n}}$ clusters is predicted to be nitric oxide (NO). The overall pathway to yield NO product, however, involves many steps. First, Al-O bond dissociation; then, $\mathrm{N}-\mathrm{N}$ bond dissociation followed by nitro-nitrite isomerization, and finally, NO elimination. Previous theoretical results suggest that isolated DMNA can follow similar nitro-nitrite isomerization pathway both on the excited as well as on the ground electronic surfaces. However, overall nitro-nitrite isomerization is found to be endothermic reaction for isolated DMNA, whereas, DMNA-Al and DMNA- $\mathrm{Al}_{2}$ clearly exhibit overall exothermic nitro-nitrite isomerization. Therefore, the decomposition behaviour of nitramine
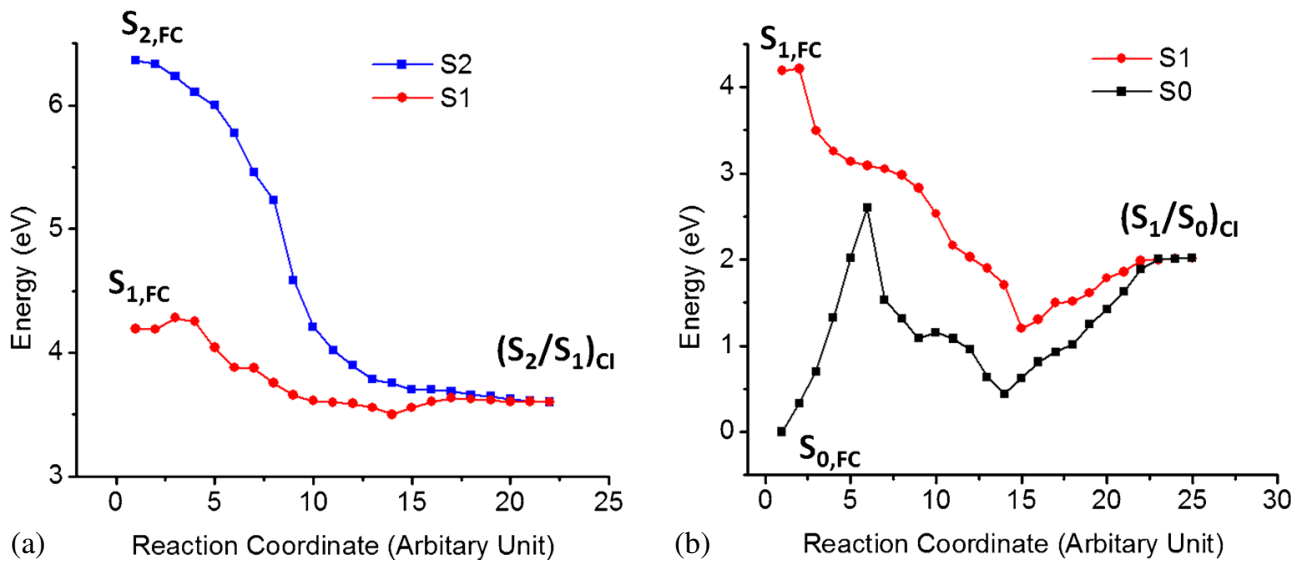

Figure 11. Energy profile diagrams obtained during optimization, computed at the CASSCF(18,15,RASSCF(1,4,1,4))//6-31G(d): (a) from $S_{2, F C}$ and $S_{1, F C}$ to $\left(S_{2} / S_{1}\right)_{C I}$; (b) from $\mathrm{S}_{1, \mathrm{FC}}$ and $\mathrm{S}_{0, \mathrm{FC}}$ to $\left(\mathrm{S}_{1} / \mathrm{S}_{0}\right)_{\mathrm{CI}}$. 
energetic moiety is predicted to be controlled by $\mathrm{Al}$ atoms. Similar behaviour can be anticipated for more complex metalized nitramine energetic materials.

Our next focus is to perform two-pulse correlation spectroscopy to decipher femtosecond dynamics of decomposition of DMNA-Al $\mathrm{n}_{\mathrm{n}}$ system. Furthermore, temperature dependent study of the excited electronic state decomposition of DMNA-Al system will be also undertaken.

\section{Acknowledgment}

Indian Institute of Science (IISc, Part-2A-XII Plan 120201-0243-01-403) and ISRO-IISc Space Technology Cell (ISTC/CIP/ATB/0333) are gratefully acknowledged for the financial support of this research.

\section{References}

1. (a) Bernstein E R 2004 In Overviews of Recent Research on Energetic materials D Thompson, $\mathrm{T}$ Brill $\mathrm{T}$ and R Shaw (Eds.) (New Jersey: World Scientific); (b) Williams F E 1971 Adv. Chem. Phys. 21 289; (c) Sharma J, Beard B C and Chaykovsky M 1991 J. Phys. Chem. 95 1209; (d) Gilman J 1995 J. Philos. Mag. B 71 1057; (e) Kuklja M M, Aduev B P, Aluker E D, Krasheninin V I, Krechetov A G and Mitrofanov A Y 2001 J. Appl. Phys. 89 4156; (f) Windawi H M, Varma S P, Cooper C B and Williams F 1976 J. Appl. Phys. 473418

2. Bhattacharya A and Bernstein E R 2011 J. Phys. Chem. A 1154135

3. Bhattacharya A, Guo Y Q and Bernstein E R 2010 Acc. Chem. Res. 431476

4. (a) Fried L E, Manaa M R, Pagoria P F and Simpson R L 2001 Annu. Rev. Mater. Res. 31 291; (b) Tilton T M, Gash A E, Simpson R L, Hrubesh L W, Satcher J H and Poco J F 2001 J. Non-Cryst. Solids 285338
5. Ramaswamy A L 2000 Combust. Explo. Shock. 36131

6. (a) Politzer P, Lane P and Grice M E 2001 J. Phys. Chem. A. 105 7473; (b) Swihart M T and Catoire L 2000 Combust. Flame 121210

7. Snyder E P and Seltz H 1945 J. Am. Chem. Soc. 67 683

8. (a) Bhattacharya A, Guo Y Q and Bernstein E R $2009 \mathrm{~J}$. Phys. Chem. A 113 811; (b) McQuaid M J, Miziolek A W, Sausa R C and Merrow C N 1991 J. Phys. Chem. 95 2713; (b) Mialocq J C and Stephenson J C 1986 Chem. Phys. Lett. 123 390; (c) Mialocq J C and Stephenson J C 1986 J. Chem. Phys. 106 281; (d) Lemire G W, Simeonsson J B and Sausa R C 1993 Anal. Chem. 65 529; (e) Simeonsson J B, Lemire G W and Sausa R C 1993 Appl. Spectrosc. 111907

9. (a) Jiang Z, Li F Q, Zhao F Q, Liu Z R, Yin C M, Luo Y and Li S W 2006 Propellants Explos. Pyrotech. 31 139; (b) Ye C C, Zhao F-Q, Xu S-Y and Ju X-H 2013 J. Mol. Model 19 2451; (c) Umezawa N, Kalia R K, Nakano A and Vashista P 2007 J. Chem. Phys. 126 234702

10. Frisch M J, Trucks G W, Schlegel H B, Scuseria G E, Robb M A, Cheeseman J R, Scalmani G, Barone V, Mennucci B, Petersson G A, Nakatsuji H, Caricato M, Li X, Hratchian H P, Izmaylov A F, Bloino J, Zheng G, Sonnenberg J L, Hada M, Ehara M, Toyota K, Fukuda R, Hasegawa J, Ishida M, Nakajima T, Honda Y, Kitao O, Nakai H, Vreven T, Montgomery J A, Peralta J E, Ogliaro F, Bearpark M, Heyd J J, Brothers E, Kudin K N, Staroverov V N, Kobayashi R, Normand J, Raghavachari K, Rendell A, Burant J C, Iyengar S S, Tomasi J, Cossi M, Rega N, Millam J M, Klene M, Knox J E, Cross J B, Bakken V, Adamo C, Jaramillo J, Gomperts R, Stratmann R E, Yazyev O, Austin A J, Cammi R, Pomelli C, Ochterski J W, Martin R L, Morokuma K, Zakrzewski V G, Voth G A, Salvador P, Dannenberg J J, Dapprich S, Daniels A D, Farkas Ö, Foresman J B, Ortiz J V, Cioslowski J and Fox D J 2009 Gaussian, Inc. (Wallingford CT)

11. McDouall J J, Peasley K and Robb M A 1988 Chem. Phys. Lett. 148183 